\title{
Introduction to the Special Edition: Intra-Sexual Selection and the Evolution of Male Facial Threat and Dominance Displays
}

\author{
Barnaby J. W. Dixson ${ }^{1}$
}

Received: 30 May 2020 / Revised: 30 May 2020 / Accepted: 3 June 2020 /

Published online: 10 June 2020

(C) Springer Nature Switzerland AG 2020

Sexual selection operates on sexually dimorphic traits inter-sexually via mate choice for attractive ornaments and intra-sexually via contest competition for weaponry and badges of status (Kokko et al. 2006). Male traits evolve via female choice by conferring indirect genetic benefits like immunity and direct benefits like resources and protection (Kokko et al. 2006). Sexual dimorphism in men's facial, bodily and vocal traits are comparable to males from species of anthropoid primates with polygynous mating systems (Dixson et al. 2005; Puts et al. 2016), large social groups and multilevel social systems (Grueter et al. 2015), suggesting some of men's secondary sexual characters are sexually selected.

While facially masculine traits may indirectly reflect men's health, women's preferences for facial masculinity are mixed (Rhodes 2006), possibly because facially masculine men seek mating opportunities over paternal provisioning (Kruger 2006). Mating strategies models propose women forego paternal investment when genetic benefits can be realised (Gangestad and Simpson 2000), including via short-term relationships (Little et al. 2011a), at the peri-ovulatory phase of the menstrual cycle (Gildersleeve et al. 2014) and when pathogen concerns are high (Little et al. 2011b). However, recent studies have not reported stronger facial masculinity preferences among women for short-term than long-term relationships (Clarkson et al. 2020; Stower et al. 2020), when pathogen concerns are high (McIntosh et al. 2017), or at the peri-ovulatory phase of the menstrual cycle (Dixson et al. 2018a; Jones et al. 2018), casting some doubt on whether indirect selection has shaped women's mate preferences. Instead, direct benefits models of mate preferences and intra-sexual selection may explain the origins of masculine facial traits (Archer 2019; Puts 2010). Indeed, dominance exerts stronger effects than attractiveness on ratings of men's masculine traits (Puts 2010) and men's actual mating success (Hill et al. 2013; Kordsmeyer et al.

Barnaby J. W. Dixson

b.dixson@uq.edu.au

1 School of Psychology, The University of Queensland, St. Lucia, Brisbane, QLD 4072, Australia 
2018), so that intra-sexual selection may have shaped men's morphology and influenced women's mate preferences.

In this special edition, the role of intra-sexual selection in shaping men's facial dominance and threat is explored in seven articles. Mefodeva et al. (2020) test how variation in facial masculinity and beardedness interact to determine men's judgments of male masculinity, dominance and aggressiveness. While facial masculinity and facial hair both increased ratings for all traits, the most feminine bearded faces received significantly higher trait ratings than the most masculine clean-shaven male faces. Further, men reporting high social dominance gave higher trait ratings to bearded than clean-shaven faces. Gray et al. (2020) also report among participants from the USA and India that beards augment perceptions of assertiveness and strength but reduce ratings of warmth and attractiveness. These data contribute to a growing body of research suggesting that intra-sexual selection has shaped male beardedness as a badge of status (Dixson et al. 2017a; Sherlock et al. 2017) rather than an attractive ornament (Dixson and Vasey 2012; Neave and Shields 2008)

Testing how sexual selection has shaped men's beardedness is complicated by oscillating trends in cultural grooming practices (Barber 2001). Pazhoohi and Kingstone (2020) use data on beardedness from over 14,000 men spanning 25 countries and report that parasite prevalence and income disparity positively predicted the frequency of full beards. Associations between parasite prevalence and beardedness were attributed to the Hamilton-Zuk hypothesis, where sexually selected traits signal genetic quality via parasite resistance (Hamilton and Zuk 1982). Experimental studies show that women's preferences for facial hair are positively associated with their selfreported pathogen disgust (McIntosh et al. 2017; Clarkson et al. 2020). Associations between beardedness and income inequality suggests a role of intra-sexual selection shaping men's grooming. Prior cross-cultural research reported beards were more frequent and women's preferences for facial higher are higher under conditions of high male-male competition (Dixson et al. 2017b, 2019). Pazhoohi and Kingstone (2020) make an important contribution to a small literature suggesting that men's grooming patterns coincide with economic and ecological factors in ways that are predicted by sexual selection theories.

The developmental processes underpinning judgments of intra-sexual formability in adulthood are often overlooked in the human sexual selection literature. Terrizzi (2020) provides an extensive and critical review of the developmental changes in perceptions of male power and dominance. As early as 2-5 years of age, children attribute power and strength to expansive body postures, facial masculinity and beardedness in men (Terrizzi et al. 2019; Nelson et al. 2019). However, prior to puberty, children are dependent on parental figures and prefer feminine over masculine adult faces (Quinn et al. 2002). During adolescence, face perceptions shift from caregivers towards peers (Picci and Scherf 2016), a higher sensitivity to angry facial expressions emerges (Motta-Mena and Scherf 2017) and judgments of masculinity and strength for bearded faces are similar to adults (Nelson et al. 2019). Terrizzi's (2020) detailed review highlights the need for further research quantifying the ontogeny of intra-sexual formidability judgments and outlines approaches for studying these perceptual trajectories in future research.

In addition to facial structure and hirsutism, threat is also communicated through facial expressions. Craig and Lee (2020) comprehensively review whether facial 
morphology interacts with facial expressions of emotion to determine the efficacy of male threat displays. Evidence from structural mechanisms, where craniofacial masculinity overlaps with angry facial expressions, are compared to stereotype mechanisms in which gender expectations are attributed to emotional expressions. An advantage for masculine facial traits in anger communication in male faces is found across studies, including experimentally enhancing masculine structure increasing perceptions of anger in male faces (Becker et al. 2007), the muscular movements that produce angry facial expressions augmenting judgments of male formidability (Sell et al. 2014) and facial hair enhancing the speed and accuracy of detecting angry facial expressions (Craig et al. 2019). Craig and Lee (2020) review face perception research from cognitive neuroscience and evolutionary psychology, providing new perspectives on how intra-sexual selection may have shaped threatening facial expressions in men.

A growing body of research highlights a role of men's physical formidability in intra-sexual contest competition over the course of human evolution (Puts et al. 2015). However, in contemporary societies direct physical confrontations may be reduced compared to rates that occurred during human ancestry (Sell et al. 2014). Reed et al. (2020) review evidence from behavioral economics that anger performs an important role in men's bargaining power during ultimatum games. Posing angry facial expressions during interpersonal conflict might add credibility to any forthcoming aggressive actions (Reed and DeScioli 2017; Reed et al. 2014). Thus, credibility is higher when anger is delivered by responders in powerful social positions and interacts in important ways with the power of individuals making proposals. Reed et al. (2020) demonstrate that intra-sexually selected threat displays can play a key role in how individuals navigate social dominance hierarchies where direct physical conflict is not the main form of conflict resolution.

Without a fossil record of hairy and fleshy traits, comparative analyses among the anthropoid primates can shed light on how sexual selection has shaped human morphology. Petersen and Higham (2020) extensively review the evolution of male facial expressions in nonhuman primates, including how aggressive and submissive displays occur within dominance based hierarchies. With regards male ornamentation, intra-sexual selection may have favoured more colourful facial characteristics in high ranking males in species with pronounced reproductive skew. In species with lower reproductive skew, female choice may play stronger a role in sexual selection shaping male facial coloration. The authors also discuss how craniofacial characters like facial width-to-height ratio (fWHR) and symmetry are associated with mate competition and mate choice. The article ends by reviewing research in humans, including how intra-sexual selection has shaped masculine fWHR (Geniole et al. 2015; Dixson 2018) and whether women's mate preferences for masculine facial traits vary over the menstrual cycle (Blake et al. 2016; Dixson et al. 2018b). Petersen and Higham (2020) provide an up to date review on intra-sexual selection among male nonhuman primates that will likely resonate with researchers studying sexual selection in humans.

One hundred and fifty years ago, Darwin (1871) proposed men's morphology and behaviors were selected via intra and inter-sexual selection. A large body of research has quantified whether women's mate preferences target masculine morphology, vocalisations and behaviors, with less attention given to how male-male competition may have exerted sexual selection on masculine characters. The articles in this special 
edition are intended to provide new data and theoretical summaries regarding how male-male competition explaines the evolution of men's facial dominance and threat from an interdisciplinary perspective to help inform contemporary research in this area.

\section{Compliance with Ethical Standards}

Conflict of Interest The author has no competing interests.

\section{References}

Archer, J. (2019). The reality and evolutionary significance of human psychological sex differences. Biological Reviews, 94, 1381-1415.

Barber, N. (2001). Mustache fashion covaries with a good marriage market for women. Journal of Nonverbal Behavior, 25, 261-272.

Becker, D. V., Kenrick, D. T., Neuberg, S. L., Blackwell, K. C., \& Smith, D. M. (2007). The confounded nature of angry men and happy women. Journal of Personality and Social Psychology, 92, 179-190.

Blake, K., Dixson, B. J. W., O’Dean, S. M., \& Denson, T. F. (2016). Standardized methodological protocols for measuring the effects of fertility on women's behavior: A data-driven approach contrasting counting and hormonal methods. Hormones and Behavior, 81, 74-83.

Clarkson, T. R., Sidari, M. J., Sains, R., Alexander, M., Harrison, M., Mefodeva, V., et al. (2020). A multivariate analysis of women's mating strategies and sexual selection on men's facial morphology. Royal Society Open Science, 7(1), 191209.

Craig, B. M., \& Lee, A. J. (2020). Stereotypes and structure in the interaction between facial emotional expression and sex characteristics. Adaptive Human Behavior and Physiology.

Craig, B. M., Nelson, N. L., \& Dixson, B. J. W. (2019). Sexual selection, agonistic signalling, and the effect of beards on men's anger displays. Psychological Science, 30, 728-738.

Darwin, C. (1871). The descent of man: And selection in relation to sex. Albemarle Street: John Murray.

Dixson, B. J. (2018). Is male facial width-to-height ratio the target of sexual selection? Archives of Sexual Behavior, 47(4), 827-828.

Dixson, B. J., \& Vasey, P. L. (2012). Beards augment perceptions of men's aggressiveness, dominance and age, but not attractiveness. Behavioral Ecology, 23, 481-490.

Dixson, A., Dixson, B., \& Anderson, M. (2005). Sexual selection and the evolution of visually conspicuous sexually dimorphic traits in male monkeys, apes, and human beings. Annual Review of Sex Research, 16, $1-19$.

Dixson, B. J. W., Lee, A. J., Sherlock, J. M., \& Talamas, S. N. (2017a). Beneath the beard: Do facial morphometrics influence the strength of judgments of men's beardedness? Evolution and Human Behavior, 38, 164-174.

Dixson, B. J. W., Rantala, M. J., Melo, E. F., \& Brooks, R. C. (2017b). Beards and the big city: Displays of masculinity may be amplified under crowded conditions. Evolution and Human Behavior, 38, 259-264.

Dixson, B. J., Blake, K. R., Denson, T. F., Gooda-Vossos, A., O’Dean, S. M., Sulikowski, D., ... \& Brooks, R. C. (2018a). The role of mating context and fecundability in women's preferences for men's facial masculinity and beardedness. Psychoneuroendocrinology, 93, 90-102.

Dixson, B. J. W., Lee, A. J., Blake, K. R., Jasienska, G., \& Marcinkowska, U. M. (2018b). Women's preferences for men's beards show no relation to their ovarian cycle phase and sex hormone levels. Hormones and Behavior., 97, 137-144.

Dixson, B. J., Rantala, M. J., \& Brooks, R. C. (2019). Cross-cultural variation in women's preferences for men's body hair. Adaptive Human Behavior and Physiology, 5, 131-147.

Gangestad, S. W., \& Simpson, J. A. (2000). The evolution of human mating: Trade-offs and strategic pluralism. Behavioral and Brain Sciences, 23, 573-587.

Geniole, S. N., Denson, T. F., Dixson, B. J., Carré, J. M., \& McCormick, C. M. (2015). Evidence from metaanalyses of the facial width-to-height ratio as an evolved cue of threat. PLoS One, 10(7).

Gildersleeve, K., Haselton, M. G., \& Fales, M. R. (2014). Do women's mate preferences change across the ovulatory cycle? A meta-analytic review. Psychological Bulletin, 140, 1205-1259. 
Gray, P. B., Craig, L. K., Paiz-Say, J., et al. (2020). Sexual selection, signaling and facial hair: US and India ratings of variable male facial hair. Adaptive Human Behavior and Physiology. https://doi.org/10.1007 /s40750-020-00134-4.

Grueter, C. C., Isler, K., \& Dixson, B. J. (2015). Are badges of status adaptive in large complex primate groups? Evolution and Human Behavior, 36, 398-406.

Hamilton, W. D., \& Zuk, M. (1982). Heritable true fitness and bright birds: A role for parasites? Science, 218, 384-387.

Hill, A. K., Hunt, J., Welling, L. L., Cárdenas, R. A., Rotella, M. A., Wheatley, J. R., ... \& Puts, D. A. (2013). Quantifying the strength and form of sexual selection on men's traits. Evolution and Human Behavior, 34(5), 334-341.

Jones, B. C., Hahn, A. C., Fisher, C. I., Wang, H., Kandrik, M., Han, C., et al. (2018). No compelling evidence that preferences for facial masculinity track changes in women's hormonal status. Psychological Science, 29, 996-1005.

Kokko, H., Jennions, M. D., \& Brooks, R. (2006). Unifying and testing models of sexual selection. Annual Review of Ecology, Evolution, and Systematics, 37, 43-66.

Kordsmeyer, T. L., Hunt, J., Puts, D. A., Ostner, J., \& Penke, L. (2018). The relative importance of intra-and intersexual selection on human male sexually dimorphic traits. Evolution and Human Behavior, 39, 424 436.

Kruger, D. J. (2006). Male facial masculinity influences attributions of personality and reproductive strategy. Personal Relationships, 13, 451-463.

Little, A. C., Connely, J., Feinberg, D. R., Jones, B. C., \& Roberts, S. C. (2011a). Human preference for masculinity differs according to context in faces, bodies, voices, and smell. Behavioral Ecology, 22, 862868.

Little, A. C., DeBruine, L. M., \& Jones, B. C. (2011b). Exposure to visual cues of pathogen contagion changes preferences for masculinity and symmetry in opposite-sex faces. Proceedings of the Royal Society B, 278, 2032-2039.

McIntosh, T. L., Lee, A. J., Sidari, M. J., Stower, R. E., Sherlock, J. M., \& Dixson, B. J. (2017). Microbes and masculinity: Does exposure to pathogenic cues alter women's preferences for male facial masculinity and beardedness? PLoS One, 12(6).

Mefodeva, V., Sidari, M. J., Chau, H., Fitzsimmons, B., Antoine, G., Clarkson, T. R., et al. (2020). Multivariate intra-sexual selection on men's perceptions of male facial morphology. Adaptive Human Behavior and Physiology. https://doi.org/10.1007/s40750-020-00128-2.

Motta-Mena, N. V., \& Scherf, K. S. (2017). Pubertal development shapes perception of complex facial expressions. Developmental Science, 20(4), e12451.

Neave, N., \& Shields, K. (2008). The effects of facial hair manipulation on female perceptions of attractiveness, masculinity, and dominance in male faces. Personality and Individual Differences, 45, 373-377.

Nelson, N. L., Kennedy-Costantini, S., Lee, A. J., \& Dixson, B. J. (2019). Children's judgements of facial hair are influenced by biological development and experience. Evolution and Human Behavior, 40, 551-556.

Pazhoohi, F., \& Kingstone, A. (2020). Parasite prevalence and income inequality positively predict beardedness across 25 countries. Adaptive Human Behavior and Physiology. https://doi.org/10.1007/s40750-02000132-6.

Petersen, R., \& Higham, J. P. (2020). The role of sexual selection in the evolution of facial displays in male non-human primates. Adaptive Human Behavior and Physiology.

Picci, G., \& Scherf, K. S. (2016). From caregivers to peers: Puberty shapes human face perception. Psychological Science, 27, 1461-1473.

Puts, D. A. (2010). Beauty and the beast: Mechanisms of sexual selection in humans. Evolution and Human Behavior, 31, 157-175.

Puts, D. A., Bailey, D. H., \& Reno, P. L. (2015). Contest competition in men. The Handbook of Evolutionary Psychology. Hoboken: Wiley.

Puts, D. A., Hill, A. K., Bailey, D. H., Walker, R. S., Rendall, D., Wheatley, J. R., ... \& Jablonski, N. G. (2016). Sexual selection on male vocal fundamental frequency in humans and other anthropoids. Proceedings of the Royal Society B, 283, 20152830.

Quinn, P. C., Yahr, J., Kuhn, A., Slater, A. M., \& Pascalis, O. (2002). Representation of the gender of human faces by infants: A preference for female. Perception, 31, 1109-1121.

Reed, L. I., \& DeScioli, P. (2017). The emotional moves of a rational actor: Smiles, scowls, and other credible messages. Games, 8(2), 18.

Reed, L. I., DeScioli, P., \& Pinker, S. A. (2014). The commitment function of angry facial expressions. Psychological Science, 25, 1511-1517. 
Reed, L. I., Okun, S., \& Cooley, C. (2020). The intrapersonal and interpersonal effects of anger in ultimatum bargaining. Adaptive Human Behavior and Physiology. https://doi.org/10.1007/s40750-020-00136-2.

Rhodes, G. (2006). The evolutionary psychology of facial beauty. Annual Reviews in Psychology, 57, 199226.

Sell, A., Cosmides, L., \& Tooby, J. (2014). The human anger face evolved to enhance cues of strength. Evolution and Human Behavior, 35, 425-429.

Sherlock, J. M., Tegg, B., Sulikowski, D., \& Dixson, B. J. (2017). Facial masculinity and beardedness determine men's explicit, but not their implicit, responses to male dominance. Adaptive Human Behavior and Physiology, 3(1), 14-29.

Stower, R. E., Lee, A. J., McIntosh, T. L., Sidari, M. J., Sherlock, J. M., \& Dixson, B. J. (2020). Mating strategies and the masculinity paradox: How relationship context, relationship status, and sociosexuality shape women's preferences for facial masculinity and beardedness. Archives of Sexual Behavior, 49, 809820.

Terrizzi, B. F. (2020). Conceptual Development and change precede adults' judgments about powerful appearance. Adaptive Human Behavior and Physiology. https://doi.org/10.1007/s40750-020-00135-3.

Terrizzi, B. F., Brey, E., Shutts, K., \& Beier, J. S. (2019). Children's developing judgments about the physical manifestations of power. Developmental Psychology, 55, 793-808.

Publisher's Note Springer Nature remains neutral with regard to jurisdictional claims in published maps and institutional affiliations. 